\title{
Implementation of SIC 2007 for the Vacancy Survey
}

\section{SUMMARY}

The article reports on the work to publish the Vacancy Survey on Standard Industrial Classification 2007 (SIC 2007). The main developments are:

- changes to the survey design have led to changes in both the industrial groupings and employment size bands used for sampling

- creation of historical series on a consistent basis with the latest data

- seasonal adjustment of the new series

- changes made to published outputs, including the impact of the revisions.

\section{Introduction}

n December 2009, the Office for National Statistics (ONS) published updated

plans for moving to the new Standard Industrial Classification 2007 (SIC 2007) that is the method of classifying businesses by their type of economic activity (see Hughes et al 2009). This included the intention to move the Vacancy Survey to SIC 2007 from February 2010. The first estimates on this basis, corresponding to the three months November 2009 to January 2010, were published in the Labour Market statistical bulletin on 17 February 2010.

This article describes how SIC 2007 was implemented for the Vacancy Survey and explains other changes made to the survey methods and publications.

\section{Changes to the survey design and sample allocation}

Like many business surveys conducted by ONS, the Vacancy Survey is stratified by industrial activity and business size. To reflect the new SIC 2007, the first major revision of the classification since 1992 and the outcome of a series of consultations across Europe since 2002, the sample design has had to be changed. The move to SIC 2007 complies with European regulations and has been pre-announced by ONS. The industry strata for the Vacancy Survey are defined by sections within SIC 2007, with the exception of section $\mathrm{G}$ (wholesale and retail trade; repair of motor vehicles and motor cycles) which is split into its three divisions given their large size. Table 1 shows the industries under the SIC 2007 survey design compared to their nearest equivalent in the original SIC 2003 survey design.

ONS also took the opportunity to standardise business size bands (based on employment) across industries, fulfilling a recommendation from the Report on the Triennial Review of the Monthly Vacancy Survey (2005). Originally, different combinations of 10 size bands were applied to different industries, which did not always align with the published size bands required under European regulation. These have now been reduced to five standard size bands across all industries in line with the published size bands (see Table 2). This improvement has caused significant revisions to the level of some of the size band estimates, increasing the proportion of vacancies reported in businesses with more than 2500 employees, while reducing the number in the 250-2499 size band. This is explained in greater detail later in the article.

For the sample, the lower size band limit was raised from businesses with employment of one, to businesses with employment of two. Businesses with employment of one are still included in the population and thus estimated for. This fulfils a recommendation from the Report on the Triennial Review of the Vacancy Survey (2009), with the aim of reducing the administrative burden on the smallest businesses.

The overall sample size remains at approximately 6,000 businesses per month 
Table 1

Industries used to stratify the Vacancy Survey: SIC 2007 compared to their nearest equivalent in SIC 2003

\begin{tabular}{|c|c|c|c|c|c|c|c|}
\hline \multirow{3}{*}{$\begin{array}{l}\text { SIC } 2003 \\
\text { Sections } \\
\text { C }\end{array}$} & \multirow{3}{*}{$\begin{array}{l}\text { Description } \\
\text { Mining and quarrying }\end{array}$} & & & \multirow{3}{*}{$\begin{array}{l}\text { SIC } 2007 \\
\text { Sections } \\
\text { B }\end{array}$} & \multirow{3}{*}{$\begin{array}{l}\text { Description } \\
\text { Mining and quarrying }\end{array}$} & \multirow{2}{*}{\multicolumn{2}{|c|}{ SIC 2007 Range }} \\
\hline & & \multicolumn{2}{|c|}{ SIC 2003 Range } & & & & \\
\hline & & 10100 & 14500 & & & 0510 & 0990 \\
\hline DA & Food, drink and tobacco & 15111 & 16000 & c & Manufacturing & 1011 & 3320 \\
\hline $\mathrm{DB} / \mathrm{DC}$ & Textiles, clothing and leather & 17100 & 19300 & & & & \\
\hline $\mathrm{DD}$ & Wood & 20100 & 20520 & & & & \\
\hline DE & Paper, pulp, printing and publishing & 21110 & 22330 & & & & \\
\hline DF & Coke, nuclear fuels, refined oil & 23100 & 23300 & & & & \\
\hline DG & Chemicals & 24110 & 24700 & & & & \\
\hline DH & Rubber and plastics & 25110 & 25240 & & & & \\
\hline DI & Non-metallic mineral products & 26110 & 26829 & & & & \\
\hline DJ & Base metals and fabricated metal products & 27100 & 28750 & & & & \\
\hline DK & Machinery and equipment & 29110 & 29720 & & & & \\
\hline $\mathrm{DL}$ & Electrical and optical equipment & 30010 & 33500 & & & & \\
\hline DM & Transport equipment & 34100 & 35500 & & & & \\
\hline DN & Manufacturing (NEC) & 36110 & 37200 & & & & \\
\hline \multirow[t]{2}{*}{$\mathrm{E}$} & Gas, electricity and water supply & 40110 & 42000 & D & Electricity, gas, steam and air conditioning supply & 3511 & 3530 \\
\hline & & & & $\mathrm{E}$ & $\begin{array}{l}\text { Water supply, sewerage, waste management and } \\
\text { remediation activities }\end{array}$ & 3600 & 3900 \\
\hline $\mathrm{F}$ & Construction & 45110 & 45500 & $\mathrm{~F}$ & Construction & 4110 & 43999 \\
\hline G & Motor Vehicles & 50101 & 50500 & G & Motor Vehicles & 4511 & 4540 \\
\hline G & Wholesale & 51110 & 51900 & G & Wholesale & 4611 & 4690 \\
\hline G & Retail & 52110 & 52740 & G & Retail & 4711 & 4799 \\
\hline $\mathrm{H}$ & Hotels and restaurants & 55101 & 55520 & I & Accommodation and food service activities & 5510 & 56302 \\
\hline I & Transport, storage & 60101 & 63400 & H & Transport and storage & 4910 & 53202 \\
\hline I & Communications & 64110 & 64200 & J & Information and communication & 5811 & 6399 \\
\hline J & Financial Intermediation & 65110 & 67200 & K & Financial and insurance activities & 6411 & 6630 \\
\hline $\mathrm{K}$ & Real estate, renting & 70110 & 70320 & L & Real estate activities & 6810 & 6832 \\
\hline \multirow[t]{2}{*}{$\mathrm{K}$} & Business activities & 71100 & $\begin{array}{l}74849 \\
\text { (exc. } 74500)\end{array}$ & M & Professional, scientific and technical activities & 6910 & 7500 \\
\hline & & & & $\mathrm{N}$ & Administrative and support service activities & 7711 & $\begin{array}{l}8299 \\
\text { (exc. 781-3) }\end{array}$ \\
\hline $\mathrm{L}$ & $\begin{array}{l}\text { Public administration and defence; compulsory social } \\
\text { security }\end{array}$ & 75110 & 75300 & 0 & $\begin{array}{l}\text { Public administration and defence; compulsory social } \\
\text { security }\end{array}$ & 8411 & 8430 \\
\hline M & Education & 80100 & 80429 & $P$ & Education & 8510 & 8560 \\
\hline $\mathrm{N}$ & Health and social work & 85111 & 85322 & Q & Human health and social work & 8610 & 8899 \\
\hline \multirow[t]{2}{*}{0} & Other community, social and personal service activities; & 90010 & 93059 & $\mathrm{R}$ & Arts, entertainment and recreation & 9001 & 9329 \\
\hline & & & & s & Other service activities & 9411 & 9609 \\
\hline
\end{tabular}

Source: Office for National Statistics

Table 2

\section{Approximate sample sizes by size band under the latest sample design}

\begin{tabular}{ll}
\hline Employment size band & Sample size \\
\hline $2-9$ & 2086 \\
$10-49$ & 978 \\
$50-249$ & 702 \\
$250-2499$ & 1056 \\
2500 and over & 1176 \\
\hline
\end{tabular}

Source: Office for National Statistics

(15,000 different businesses per quarter). The sample was allocated across the new sample design, using a method that minimises the variance at the total level but also gives good estimates for subgroups. This objective is balanced by following ONS guidance to minimise the administrative burden and ensure the confidentiality of respondents. The achieved sample by size band is shown in Table 2.

The sample rotates for businesses below a certain size depending on the industry:

- for most industries in the new design, sample rotation occurs for businesses below employment of 2500

- for section B (mining and quarrying) and section $\mathrm{E}$ (water supply, sewerage waste and remediation), the cut-off is employment of 250

- for section D (electricity, gas, steam and air conditioning supply), the cut-off is employment of 50

The lower cut-offs in sections B, D and E are because the business population in these relatively small industries cannot support rotational sampling above these thresholds.
All businesses in the population above the sampling cut-off are selected every month. Businesses sampled below the cut-off are selected once a quarter, and remain in the sample for a number of consecutive quarters before being rotated out. There are three separate samples, one for each month of the quarter, which are combined in the rolling three-month average series. Due to the changes in classification and sample design, businesses might remain in the sample for a shorter or longer period than would usually be expected, but ONS has attempted to minimise those occurrences.

\section{Constructing continuous series over time}

Continuous time series are required in order to ensure comparability of estimates over time. ONS used a combination of the following three methods for different time spans, which have then been linked to form a continuous time series: 
1. from the start of the series in April 2001 to January 2008, a conversion matrix was used (in fact series were produced up to September 2009 to give an overlap with the second method to enable the linking process). This method apportions the SIC 2003 series to SIC 2007 sections, using proportions derived from dual coded employment data in the Inter-Departmental Business Register (IDBR). This aggregate level method was widely used by ONS at the last major classification change and is widely used by other National Statistics Institutes

2. from February 2008 to December 2009, a micro-method was used. The individual survey responses selected under the original design were reweighted and aggregated using the new sample design with strata based on SIC 2007 and the new five standard size bands. This method was deemed to give better estimates than the first method. It was only applicable from the start of 2008, when businesses were first dual coded on the IDBR for both SIC 2003 and SIC 2007

3. from January 2010, the survey was selected, weighted and aggregated using the new design

The series produced from the first and second methods were joined by applying linking factors. These were calculated by taking the ratio of the data calculated by the second method with the first method for the overlapping data points between February 2008 to September 2009, producing 12 month rolling averages of these ratios, and then selecting a robust rolling average based on the nine spans. The link factors were applied backwards from January 2008 to the series generated from the first method, and then attached to the latter part of the series generated by the second method. In effect, the level of the linked series was set by the second method. Because this is a micro-method it gives the best estimate of the level of SIC 2007 series. However, this differs to the total level when estimated using SIC 2003 industries. Consequently there were revisions across the whole length of the series, at both subgroup and aggregate levels.

The linking process was applied to the industry and size band series. The size band series were then constrained to the sum of the industry series, to remove small differences between the sum of the industry series and the sum of the size band series. No linking between the second and third methods was undertaken because there were no overlapping periods - the selection switched over to the new design in January 2010. There do not appear to be any discontinuities at this point.

\section{Seasonal adjustment review}

Seasonal adjustment reviews of the Vacancy Survey are carried out each year, usually in the April release. Given the described changes in moving the survey on to a SIC 2007 basis, it was necessary to conduct a seasonal adjustment review on the revised series ahead of the February 2010 release. The review involves looking at each component and aggregate series individually to determine the type of adjustment to be used, identifying the seasonal pattern and any other effects on the data that are not strictly seasonal. A number of improvements were identified which also contributed to revisions to the seasonally adjusted series.

In addition, the review has resulted in modifications to the seasonal adjustment modelling options in all the series. An additive decomposition has been adopted for the total vacancies seasonally adjusted series. Analysis of the 20 industry series has resulted in eight series adopting a multiplicative decomposition, seven series an additive composition, with the remaining five showing no seasonality. The five 'size of enterprise' series have three with a multiplicative decomposition and two with an additive decomposition. (see Box 1, Seasonal adjustment using X12 ARIMA). As a consequence, seasonally adjusted figures have been revised back to the beginning of the series.

Revisions to the seasonally adjusted series have been relatively small and have had little effect on the assessment of the latest trends.

\section{Impact of changes}

The impact of the changes to the continuous back series on the total non-seasonally adjusted series, and the subsequent revisions to the total seasonally adjusted series, are shown in Table 3. These are also illustrated in Figure 1, which shows the old unadjusted vacancy series, the revised unadjusted vacancy series, the old seasonally adjusted vacancy series and the revised seasonally adjusted vacancy series.

The main impact on the size band analysis has been to increase the proportion of the total vacancies that are in businesses with more than 2,500 employees, while reducing the number in the 250-2,499 employee size band. This is because the previous methodology was generally overattributing vacancies within cells that straddled size bands to the smaller category. Changes in the number of vacancies in other size bands are much smaller than the movement between these two. Figure 2 shows the seasonally adjusted figures for each of the size bands before and after the changes to the sample design.

\section{Changes to published tables}

The introduction of SIC 2007 required some changes to the tables published in the Statistical Bulletin to reflect the new

\section{Box 1 \\ Seasonal adjustment using X-12 ARIMA}

Seasonal adjustment is the process of identifying and removing the seasonal components from a series leaving the trend and irregular components.

The Vacancy Survey series are seasonally adjusted using X-12 ARIMA. In future this program will be used across ONS as the logical replacement for X-11 ARIMA, due to its superior power and additional capabilities. It is now being introduced for some new series where practical.

The program splits the series into a trend, seasonal, and irregular components. If the series is modelled additively, summing the three parts gives the unadjusted data. If it is modelled multiplicatively, the raw data is the product of the three components. The seasonal component cannot be found without knowing the trend component. Therefore, $\mathrm{X}$-12 ARIMA performs a series of iterations, obtaining a better estimate for the trend and seasonality with each one.

The ARIMA functionality can be used with series of five years or more. The program fits an autoregressive integrated moving average (ARIMA) model to the data, using forecasts for one year ahead to improve the estimation of seasonal factors at the end of the series. 
Table 3

Revisions to Vacancy Survey series, April 2001 to December 2009

Thousands and per cent (three-month averages)

\begin{tabular}{rrrrrr}
\hline \multicolumn{2}{c}{ Non- seasonally adjusted series } & \multicolumn{2}{c}{ Seasonally adjusted series } \\
\hline Revised Series & Change & Change & Revised Series & Change & Change \\
$(000 \mathrm{~s})$ & $(000 \mathrm{~s})$ & (per cent) & $(000 \mathrm{~s})$ & $(000 \mathrm{~s})$ & $($ per cent) \\
\hline
\end{tabular}

Apr-Jun 2001

May-Jul 2001

Jun-Aug 2001

Jul-Sep 2001

Aug-Oct 2001

Sep-Nov 2001

Oct-Dec 2001

Nov-Jan 2002

Dec-Feb 2002

Jan-Mar 2002

Feb-Apr 2002

Mar-May 2002

Apr-Jun 2002

May-Jul 2002

Jun-Aug 2002

Jul-Sep 2002

Aug-Oct 2002

Sep-Nov 2002

Oct-Dec 2002

Nov-Jan 2003

Dec-Feb 2003

Jan-Mar 2003

Feb-Apr 2003

Mar-May 2003

Apr-Jun 2003

May-Jul 2003

Jun-Aug 2003

Jul-Sep 2003

Aug-Oct 2003

Sep-Nov 2003

Oct-Dec 2003

Nov-Jan 2004

Dec-Feb 2004

Jan-Mar 2004

Feb-Apr 2004

Mar-May 2004

Apr-Jun 2004

May-Jul 2004

Jun-Aug 2004

Jul-Sep 2004

Aug-Oct 2004

Sep-Nov 2004

Oct-Dec 2004

Nov-Jan 2005

Dec-Feb 2005

Jan-Mar 2005

Feb-Apr 2005

Mar-May 2005

Apr-June 2005

May-Jul 2005

Jun-Aug 2005

Jul-Sep 2005

Aug-Oct 2005

Sep-Nov 2005

Oct-Dec 2005

Nov-Jan 2006

Dec-Feb 2006

Jan-Mar 2006

Feb-Apr 2006

Mar-May 2006

Apr-June 2006

\section{6}

676

664

672

666

651

596

557

63

83

604

602

613

615

615

619

636

1.4
1.4
1.4
1.2

670
664
(per cent)

$10 \quad 1.5$


Table 3 continued

Revisions to Vacancy Survey series, April 2001 to December 2009

United Kingdom

Thousands and per cent (three-month averages)

\begin{tabular}{rrrrrr}
\hline \multicolumn{2}{c}{ Non- seasonally adjusted series } & \multicolumn{2}{c}{ Seasonally adjusted series } \\
\hline Revised Series & Change & Change & Revised Series & Change & Change \\
$(000 \mathrm{~s})$ & $(000 \mathrm{~s})$ & (per cent) & $(000 \mathrm{~s})$ & $(000 \mathrm{~s})$ & (per cent) \\
\hline
\end{tabular}

Aug-Oct 2006

Sep-Nov 2006

Oct-Dec 2006

Nov-Jan 2007

Dec-Feb 2007

Jan-Mar 2007

Feb-Apr 2007

Mar-May 2007

Apr-June 2007

May-Jul 2007

Jun-Aug 2007

Jul-Sep 2007

Aug-Oct 2007

Sep-Nov 2007

Oct-Dec 2007

Nov-Jan 2008

Dec-Feb 2008

Jan-Mar 2008

Feb-Apr 2008

Mar-May 2008

Apr-June 2008

May-Jul 2008

Jun-Aug 2008

Jul-Sep 2008

Aug-Oct 2008

Sep-Nov 2008

Oct-Dec 2008

Nov-Jan 2009

Dec-Feb 2009

Jan-Mar 2009

Feb-Apr 2009

Mar-May 2009

Apr-June 2009

May-Jul 2009

Jun-Aug 2009

Jul-Sep 2009

Aug-Oct 2009

Sep-Nov 2009

Oct-Dec 2009

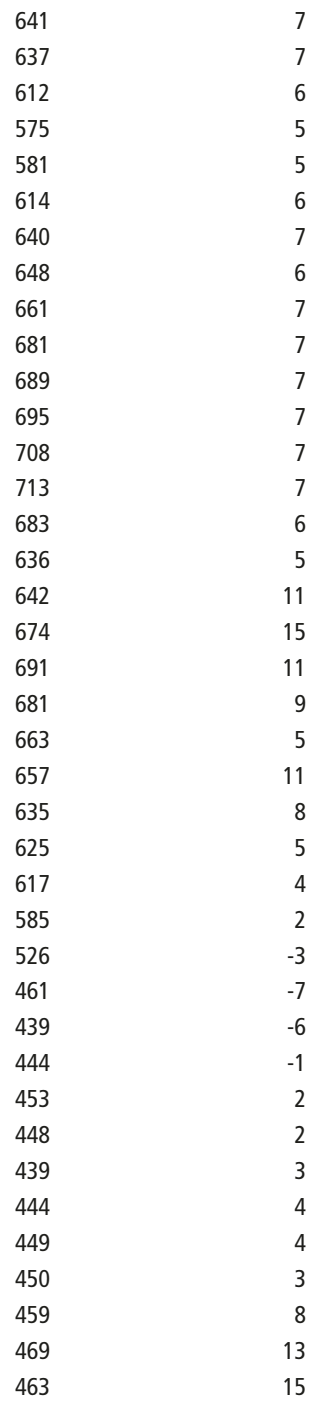

\begin{tabular}{|c|c|c|c|}
\hline 1.2 & 611 & 7 & 1.2 \\
\hline 1.1 & 609 & 7 & 1.1 \\
\hline 1.0 & 612 & 8 & 1.3 \\
\hline 0.9 & 616 & 4 & 0.7 \\
\hline 0.9 & 625 & 5 & 0.8 \\
\hline 1.0 & 639 & 3 & 0.5 \\
\hline 1.0 & 643 & 5 & 0.8 \\
\hline 1.0 & 647 & 6 & 0.9 \\
\hline 1.0 & 656 & 7 & 1.0 \\
\hline 1.0 & 666 & 7 & 1.1 \\
\hline 1.0 & 674 & 11 & 1.6 \\
\hline 1.0 & 676 & 10 & 1.5 \\
\hline 1.0 & 678 & 11 & 1.6 \\
\hline 1.0 & 685 & 10 & 1.5 \\
\hline 0.9 & 684 & 9 & 1.3 \\
\hline 0.9 & 677 & 0 & 0.0 \\
\hline 1.7 & 685 & 5 & 0.8 \\
\hline 2.3 & 697 & 9 & 1.3 \\
\hline 1.6 & 692 & 9 & 1.3 \\
\hline 1.3 & 679 & 8 & 1.1 \\
\hline 0.8 & 659 & 5 & 0.8 \\
\hline 1.7 & 642 & 10 & 1.6 \\
\hline 1.3 & 621 & 12 & 1.9 \\
\hline 0.9 & 607 & 7 & 1.1 \\
\hline 0.7 & 587 & 3 & 0.6 \\
\hline 0.4 & 558 & 0 & 0.0 \\
\hline-0.5 & 528 & 0 & 0.0 \\
\hline-1.4 & 503 & 0 & 0.0 \\
\hline-1.5 & 482 & 2 & 0.4 \\
\hline-0.2 & 466 & 2 & 0.5 \\
\hline 0.4 & 454 & 1 & 0.2 \\
\hline 0.5 & 446 & 1 & 0.2 \\
\hline 0.6 & 435 & 1 & 0.3 \\
\hline 1.0 & 430 & 0 & -0.1 \\
\hline 0.8 & 436 & 3 & 0.7 \\
\hline 0.8 & 431 & 0 & -0.1 \\
\hline 1.8 & 430 & 0 & -0.1 \\
\hline 2.8 & 441 & 5 & 1.1 \\
\hline 3.3 & 465 & 17 & 3.9 \\
\hline
\end{tabular}

Source: ONS Vacancy Survey

\section{Figure 1}

Number of job vacancies in the UK, three-month averages

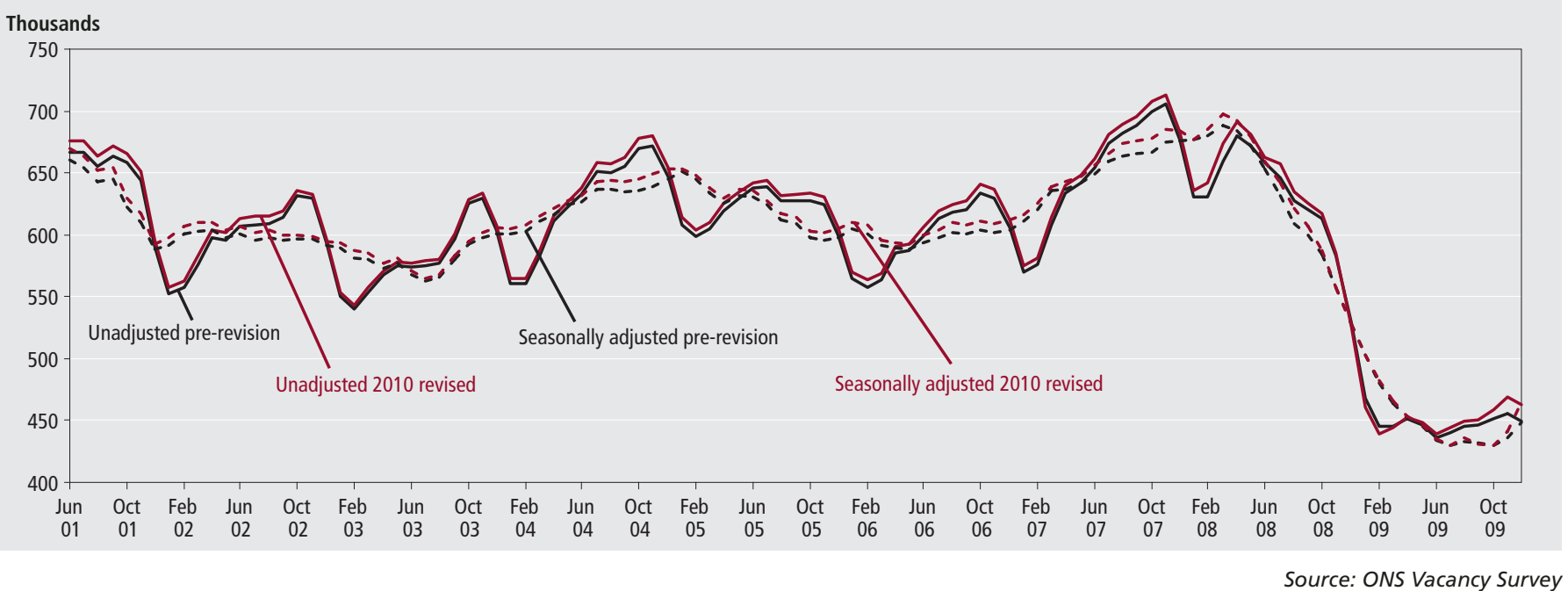




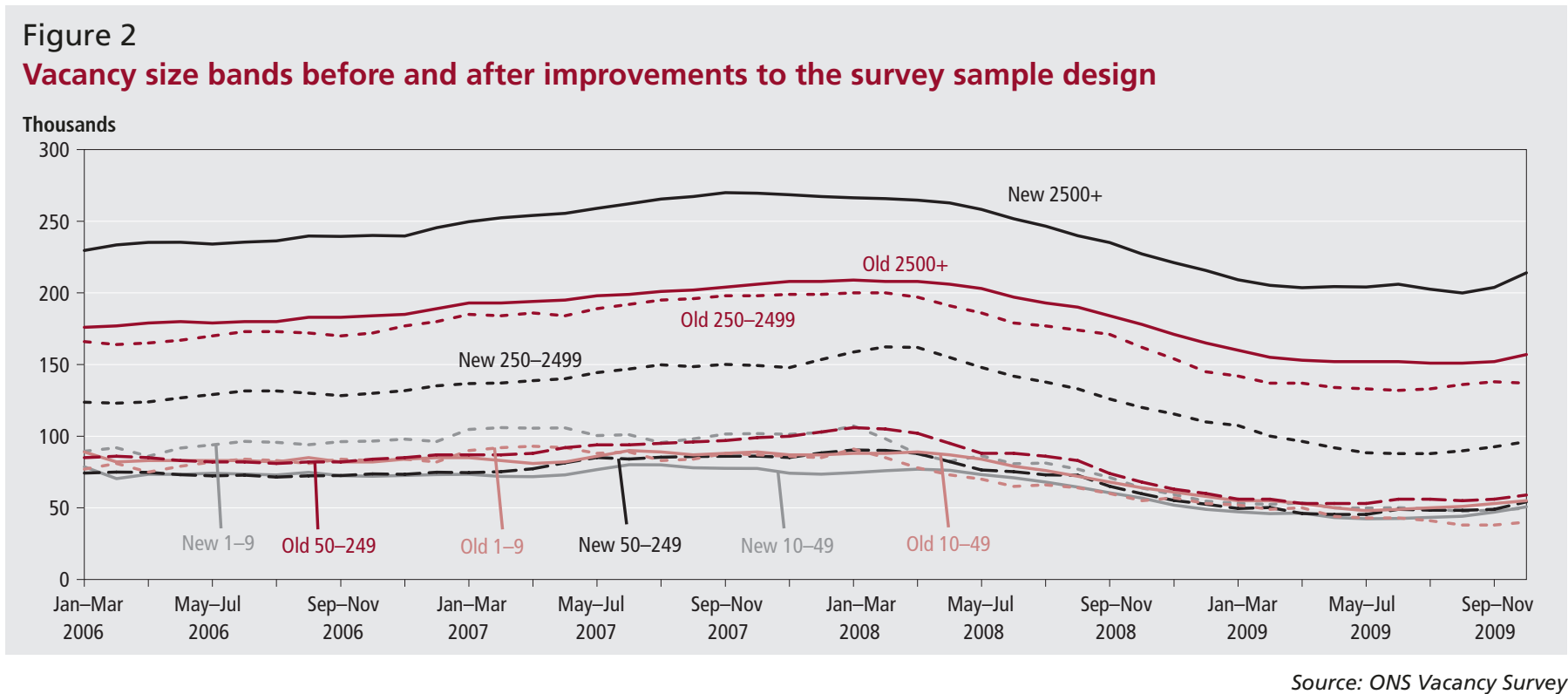

industry breakdown. At the same time ONS took the opportunity to implement other changes to the published outputs, based on the recommendations of the Report on the Triennial Review of the Vacancy Survey (2009) and an internal review of all Labour Market statistical outputs.

One of the outcomes of these reviews was that users would like to see information at a more detailed level of industrial breakdown than the eight broad industrial groupings that were previously published. These groupings reflected the level at which seasonal adjustment of the industrial series was carried out. Under SIC 2007, the publication has been moved from these broad industrial groupings to 18 individual sections. Consequently this has required the seasonal adjustment of a larger number of industrial series. The new breakdowns will give the user more information on the relative performance of the different industry sections than was previously available. However, the more detailed breakdown does mean that for some smaller sectors little variation in the published estimate of vacancies is likely to be seen over time.

Another recommendation of the 2009 triennial review was the removal of the single month series in favour of the rolling three-month average. The design of the Vacancy Survey is optimised to produce rolling three-monthly average estimates.
Although single month estimates are possible from the series and have been published in the past, the relatively high sampling variability of these estimates make it difficult to conclude to what extent movements are reflecting real variations in the labour market. Therefore rather than continue to publish this series, which may lead to spurious conclusions about the state of the labour market, ONS will only publish the rolling three-month average estimates that the survey is designed to produce.

In place of the single month series, ONS have introduced two new tables to the Labour Market statistical bulletin. The first of these is a table giving the breakdown of vacancies by the size of business, as measured by the number of employees working for the business. Although not in the Statistical Bulletin, this table has previously been published in ELMR as Table 6.25 in the section on Further Labour Market Statistics. However as explained, due to changes to the sample design, the methodology used to produce this table has now improved, leading to significant revisions from the previous versions. This table is now additionally included as Table 21 in the Statistical Bulletin.

A second new table introduces a ratio of the number of unemployed people per vacancy. Although not all people who will apply for vacancies will be unemployed, this will give some indication of the supply and demand relationship prevalent in the labour market. This new table will appear as Table 21(1) of the Statistical Bulletin. The periods available in this table differ from the other vacancy tables to reflect the latest unemployment figures available in Table 1 of the Statistical Bulletin. This means that the latest figures will always be one month behind the other vacancy tables. This new table has also replaced Table 6.25 of the ELMR tables.

\section{CONTACT}

凶)elmr@ons.gov.uk

\section{REFERENCES}

Hughes J C, James G, Evans A and Prestwood D (2009) 'Implementation of Standard Industrial Classification 2007: December 2009 update', Economic and Labour Market Review December 2009. Available at www.statistics.gov.uk/elmr/12_09/ downloads/ELMR_Dec09_Hughes.pdf

Report on the Triennial Review of the Monthly Vacancy Survey (2005). Available at www.statistics.gov.uk/downloads/theme_ other/VacancyTriennialReviewReport.pdf

Report on the Triennial Review of the Vacancy Survey (2009). Available at www.statistics.gov.uk/downloads/theme other/VacancyTriennialReviewReport2009a. pdf 